\title{
Prevalence and risk factors for bone loss in rheumatoid arthritis patients from South China: modeled by three methods
}

\author{
Zhuoran Hu${ }^{1} \mathbb{D}$, Lei Zhang ${ }^{2}$, Zhiming Lin ${ }^{1} \mathbb{D}$, Changlin Zhao ${ }^{3}$, Shuiming $\mathrm{Xu}^{4}$, He Lin ${ }^{5}$, Jiejing Zhang ${ }^{2}$, \\ Wenjie $\mathrm{Li}^{2^{*}}$ and Yongliang $\mathrm{Chu}^{2^{*}}$ (i)
}

\begin{abstract}
Background: To explore the prevalence of bone loss among patients with rheumatoid arthritis (RA) and healthy controls $(\mathrm{HC})$ and further explored the risk factors for osteopenia and osteoporosis of RA patients.

Methods: A cross-sectional survey was undertaken in four hospitals in different districts in South China to reveal the prevalence of bone loss in patients. Case records, laboratory tests, and bone mineral density (BMD) results of patients were collected. Traditional multivariable logistic regression analysis and two machine learning methods, including least absolute shrinkage selection operator (LASSO) and random forest (RF) were for exploring the risk factors for osteopenia or osteoporosis in RA patients.

Results: Four hundred five patients with RA and $198 \mathrm{HC}$ were included. RA patients had lower BMD in almost BMD measurement sites than healthy controls; the decline of lumbar spine BMD was earlier than HC. RA patients were more likely to comorbid with osteopenia and osteoporosis ( $p$ for trend $<0.001$ ) in the lumbar spine than HC. Higher serum 25-hydroxyvitamin D3 level and using tumor necrosis factor inhibitor in the last year were protective factors; aging, lower body mass index, and increased serum uric acid might be risk factors for bone loss.

Conclusions: RA patients were more prone and earlier to have bone loss than HC. More attention should be paid to measuring BMD in RA patients aging with lower BMI or hyperuricemia. Besides, serum vitamin D and all three measurement sites are recommended to check routinely. TNFi usage in the last year might benefit bone mass.
\end{abstract}

Keywords: Arthritis, rheumatoid, Osteoporosis, Prevalence, Risk factor

\section{Background}

Rheumatoid arthritis (RA) is a chronic inflammatory autoimmune disease characterized by persistent synovitis and the progressive destruction of bones and cartilage in multiple joints [1]. Osteoporosis (OP) is a well-known extra-articular complication in patients with RA [2], except for pulmonary involvement, cutaneous manifestations, and cardiovascular disease. The disorder of tumor

\footnotetext{
*Correspondence: 814022509@qq.com; chuyongliang@163.com ${ }^{2}$ Division of Rheumatology, Zhuhai Hospital of Guangdong Provincial Hospital of Chinese Medicine, No.53, Ji'Da Jingle Road, Xiangzhou District, Zhuhai City 519015, China

Full list of author information is available at the end of the article
}

necrosis factor- $\alpha$ (TNF- $\alpha)$, a key proinflammatory cytokine in RA, can stimulate osteoclastogenesis via receptor activator of nuclear factor kappa B ligand (RANKL) activation. As a result, RA patients with OP increased the risk of osteoporotic fracture (OPF), an outcome that impairs quality of life and leads to mortality $[3,4]$. The 1year cumulative mortality rate due to hip OPF in RA patients was reported to be approximately $20 \%$ and significantly higher than that in general population [5]. Accordingly, appropriate management of OP and osteopenia for preventing fragility fracture in patients with RA are crucial to optimize clinical outcome [6].

(c) The Author(s). 2021 Open Access This article is licensed under a Creative Commons Attribution 4.0 International License, which permits use, sharing, adaptation, distribution and reproduction in any medium or format, as long as you give appropriate credit to the original author(s) and the source, provide a link to the Creative Commons licence, and indicate if changes were made. The images or other third party material in this article are included in the article's Creative Commons licence, unless indicated otherwise in a credit line to the material. If material is not included in the article's Creative Commons licence and your intended use is not permitted by statutory regulation or exceeds the permitted use, you will need to obtain permission directly from the copyright holder. To view a copy of this licence, visit http://creativecommons.org/licenses/by/4.0/ The Creative Commons Public Domain Dedication waiver (http://creativecommons.org/publicdomain/zero/1.0/) applies to the data made available in this article, unless otherwise stated in a credit line to the data. 
The frequency of OP in patients with RA has been reported from 11 to $38.9 \%$ in the lumbar spine and from 6.3 to $36.2 \%$ in the total hip $[3,4,7,8]$, and the risk of developing into OP in RA patients are nearly twice compared with the general population [3]. Traditional risk factors, like age and low body mass index (BMI), and disease-specific risk factors, including glucocorticoids (GCs) treatment, immobilization, reduced physical activity due to tender joints, and muscle weakness, were frequently reported [9-12]. TNF inhibitor (TNFi), one of the representative biological disease-modifying antirheumatic drugs, has been reported either improvement or stable BMD among TNFi users in several prospective studies $[13,14]$.

However, insufficient information is available for the frequency of osteopenia and the distribution of bone mineral density (BMD) in three sites of BMD measurement in RA patients in China [15-17]. Therefore, we undertook a cross-sectional survey in four hospitals from different South China districts to explore the prevalence of bone loss and investigate BMD's differences among patients with RA and healthy controls (HC). Meanwhile, we explored the risk factors for osteopenia and OP of RA patients, modeled with conventional logistic regression and another two machine-learning modeling methods to ensure robustness.

\section{Methods}

\section{Patients}

We included the RA in-patients in four hospitals from October 2018 to August 2019 in the Third Affiliated Hospital of Sun Yat-sen University, Zhuhai Hospital of Guangdong Chinese Medicine, Ganzhou Municipal Hospital, and Fujian Provincial Hospital. The population of interest was 18 or older and diagnosed with RA (satisfied the 2010 ACR / EULAR classification criteria [18]). Age, gender-matched $\mathrm{HC}$ were contemporarily and randomly reviewed and selected from healthy-check files with DXA results in four centers in the same period. For RA patients and $\mathrm{HC}$ with more than one admission or record in the study period, only data from the first admission or record were analyzed. Exclusion criteria included when participants were unable to answer questions, pregnant, with parathyroid disorders, with a malignant tumor, refused to write informed consent or refused to have a dual-energy X-ray absorptiometry (DXA). The principal center was the Third Affiliated Hospital, Sun Yat-sen University. The detailed study flow diagram is shown in Fig. 1. Laboratory tests and DXA were done as parts of clinical routines.

\section{Main outcome variable}

BMD, $T$-score, and the $Z$-score of the lumbar spine 2-4, femoral neck (right), and total hip (both sides) were collected from DXA reports (Hologic Discovery A densitometer, Badford, MA, USA) after blood samples had been taken. In our study, the diagnosis based on the results of BMD is the outcome variable. According to the World Health Organization [19], the definition of the Tscore and the $Z$-score generates the results of BMD. A $T$-score $\geq-1.0$, between -1.0 and -2.5 , and $\leq-2.5$ represent the expected condition, osteopenia, and osteoporosis, respectively, as a diagnosis standard for men aged and over 50 and postmenopausal women. Meanwhile, the $Z$-score is used for premenopausal women and males aged under 50. A $Z$-score of -2.0 or lower indicates a lower BMD compared to the peers ('score below the expected range for age'). Therefore, both $\mathrm{HC}$ and patients were divided into two subgroups (normal BMD or impaired BMD) regardless of age and menopausal status; then stratified these two subgroups into five ones by BMD results taking age and menopausal status into account, namely "score below the expected range of age" or normal BMD in premenopausal women and men aged < 50; "osteopenia", "osteoporosis" and normal BMD in postmenopausal women and men aged $>=50$.

\section{Covariates}

Thirty-three independent variables (Table 1) were also collected, values belonged to the BMD measurement time. Smoking and drinking habits, medical and medication history, and laboratory examinations were taken from each participant's history. Dyslipidemia included hypercholesteremia and hypertriglyceridemia. 'Chronic usage' of non-steroidal anti-inflammatory drugs (NSAI Ds) or GC was defined as consecutively taking these medications at least the last 3 months. 'Rheumatoid factor positive' was defined when the concentration reached or over $30 \mathrm{IU} / \mathrm{ml}$; anti-cyclic citrullinated peptide antibodies (anti-CCP), antikeratin antibodies (AKA), and anti-RA33 antibodies (RA33) 'positive' was defined when their concentrations were at or over $20 \mathrm{IU} / \mathrm{ml}$. Insufficiency and deficiency (hypovitaminosis) of vitamin D were defined when serum 25-hydroxyvitamin D level is under $75 \mathrm{nmol} / \mathrm{L}(30 \mathrm{ng} / \mathrm{ml})$ and $50 \mathrm{nmol} / \mathrm{L}(20 \mathrm{ng} / \mathrm{ml})$ [20], respectively. Ethical approval was obtained from the Ethics Committee of the Third Affiliated Hospital of Sun Yat-sen University (Guangzhou, China). The registration no. of ethics approval of the study was [2018]02283-01. Written informed consent was obtained from all individuals participating in this study.

\section{Sample size}

The sample sizes were estimated by PASS 15 software (https://www.ncss.com, module 'test for two proportions'), with the statistical power $(1-\beta)$ set 0.90 , type I error $(\alpha)$ set 0.05 . Since HC data (total 200, 2 was omitted because their menopausal status was unknown) was collected first, we used 


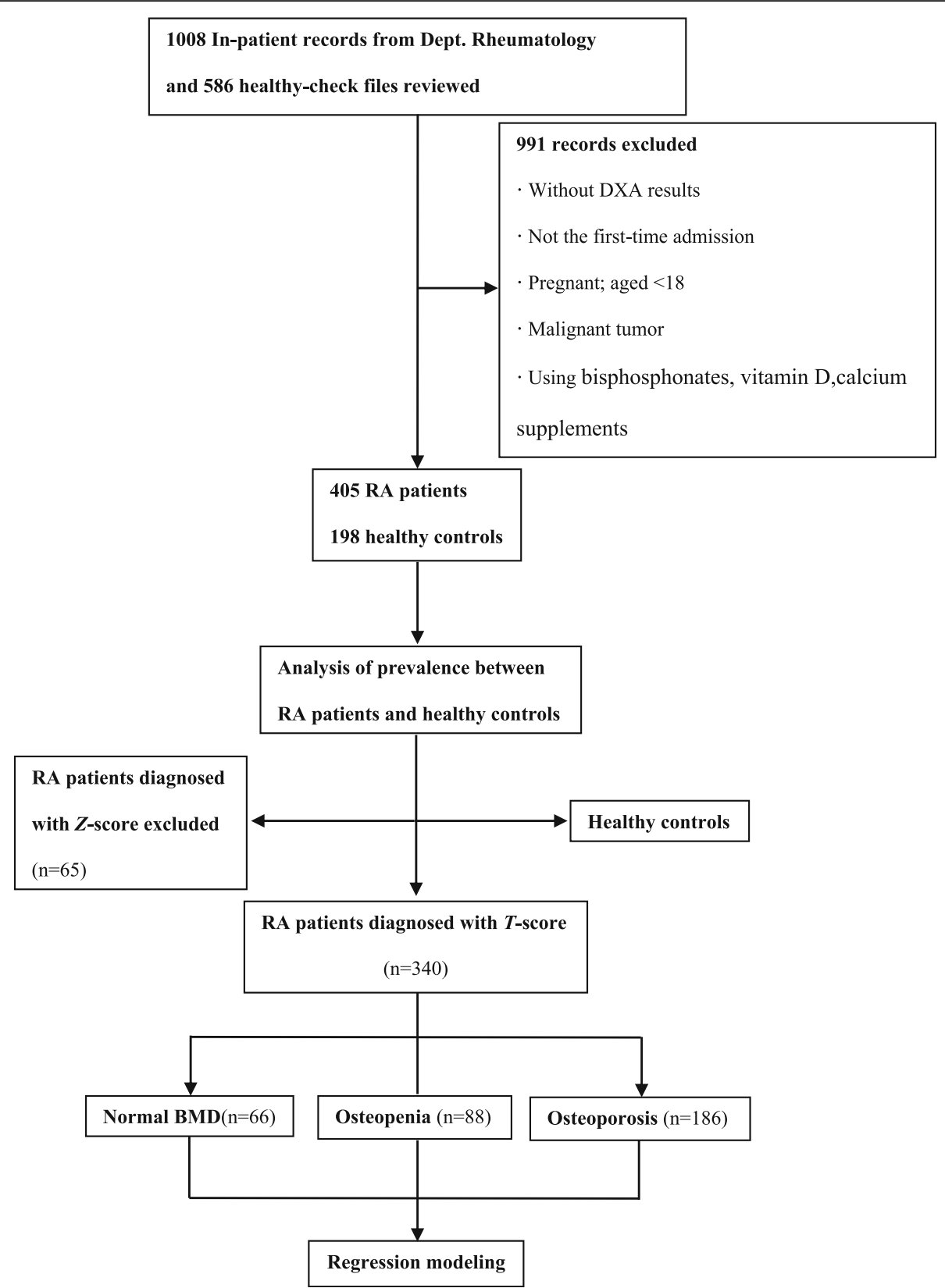

Fig. 1 Study flow diagram. Diagnosed with T-score: for those are post-menopausal women and men aged $\geq 50$. Diagnosed with Z-score: for those are pre-menopausal women and men aged $<50$

the 'Enter N1 solve for N2' function to calculate the sample size of patients. Assuming that the prevalence of complicating with OP was $40 \%$ [8] among RA patients and was $23.2 \%$ among healthy Southern Chinese [21], the software eventually calculated that a sample size of RA patients was at least 149 would suffice. To ensure adequate events of each subgroup, we finally recruited 405 patients for the present study.

\section{Statistical analysis}

Data were manually entered into EpiData (http://www. epidata.dk/) and then imported into Microsoft Office
Excel (version 2016). Two physicians rechecked and transferred this data to the R software (version 3.6.1) for analysis. Continuous variables are marked as the mean \pm standard deviation $(\mathrm{SD})$, while discrete variables are presented as frequency and percentage. Dependent variables / primary outcomes were the T-score, Z-score, and corresponding diagnoses of BMD of the lumbar spine, femoral neck, and total hip, divided and stratified as mentioned above. A two-tailed t-test was used for comparing normally distributed continuous variables, and the Kruskal-Wallis $H$ test was for non-normally 
Table 1 Candidate variables

\begin{tabular}{|c|c|}
\hline Domains & Variables $^{\mathrm{a}}$ \\
\hline $\begin{array}{l}\text { Demographics and } \\
\text { lifestyles }\end{array}$ & (1) age, (2) BMI, (3) gender, (4) smoker, always or never/seldom, (5) drinking, always or never/seldom \\
\hline Medical history ${ }^{\mathrm{b}}$ & $\begin{array}{l}\text { (6) hypertension, (7) diabetes mellitus, (8) coronary heart disease, (9) hyperuricemia, (10) dyslipidemia, (11) femoral neck } \\
\text { necrosis }\end{array}$ \\
\hline $\begin{array}{l}\text { Medication history of RA } \\
\text { patients }^{\mathrm{b}}\end{array}$ & $\begin{array}{l}\text { (12) chronic NSAIDs usage, (13) chronic GC usage, (14) types of cDMARDs recently taking, (15) TNFi usage in the last } \\
\text { one year, (16) overall anti-osteoporotic medication history }{ }^{\mathrm{b}} \text {, } \\
\text { (17) disease duration }\end{array}$ \\
\hline Laboratory & 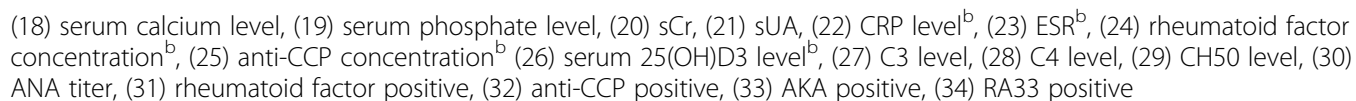 \\
\hline
\end{tabular}

BMI Body mass index, NSAIDs Non-steroidal anti-inflammatory drugs, GC Glucocorticoid, cDMARDs Conventional disease-modifying anti-rheumatic drugs, TNFi Tumor necrosis factor-a inhibitor, $s C r$ Serum creatine level, sUA Serum uric acid level, CRP C-reactive protein, ESR Erythrocyte sedimentation rate, anti-CCP Anticyclic citrullinated peptide antibodies, AKA Antikeratin antibodies, RA33 Anti-RA33 antibodies, C3 Complement component 3, C4 Complement component 4, CH50 Serum total complement activity, ANA Antinuclear antibodies

${ }^{a}$ All variables were included in statistics-driven (LASSO) and random forest model. Except from variable 1,2,16-29, all variables were categorial or dichotomous ${ }^{\mathrm{b}}$ Factors selected for the clinical knowledge-preselected model

distributed ones. Pearson's $\chi^{2}$ or Fisher's exact test was performed for categorical variables and the CochranArmitage trend test for appropriate ordinal variables. $\mathrm{R}$ (version 3.6.1) was used for statistical analyses, and statistical significance was assumed at the $p<0.05$ level.

\section{Model development}

Owing to the inadequate amount of young RA patients, predictive models were only created for RA patients whose BMD was diagnosed with T-score. We took three different approaches of regression model development to ensure the robustness and validity of the regression models: clinical knowledge-driven, conventional logistic regression models (model A), least absolute shrinkage and selection operator (LASSO, model B), and random forest (RF, model C). We separated the data of all subgroups randomly into training sets $(70 \%)$ and verification sets $(30 \%)$, with the same positive-event proportion; the training set was for modeling, and the other was for validation, which could be evaluated by C-statistics, calibration slope, and the accuracy.

Model A: We preselected and then entered candidate variables based on existing literature or well-established risk factors into logistic regression models. The final set of variables included only those with a $p$-value $<0.05$ from the regression analysis. 'glm' function in the basic package of $R$ would be used.

Model B: LASSO is an ideal method to improve multicollinearity [22]. The LASSO procedure (especially for determining the optimal shrinkage estimator) underwent 5 -fold cross-validation to avoid over-fitting. We entered all 34 candidate variables into the LASSO models. Package 'glmnet', function 'cv.glmnet' [23] would be used.

Model C: Random forest model assembles hundreds of more classification trees with a selection of correlates randomly [24]. We applied all 34 variables into the random forest models. The out-of-bag (OOB) estimates error rates; the Gini index was used to refer to the relative importance of the correlates after features were randomly permuted [25]. We identified the covariates by an increase in the Gini index by $>5$. Package 'randomForest' would perform the modeling.

\section{Results}

\section{Clinical features}

Data of 405 patients with RA and $198 \mathrm{HC}$ were included in the first step analysis. Missing data occurred only in part of DXA's measurement sites; 12 of 198 healthy subjects $(6.1 \%)$ included in the first step analysis, and 8 of 405 patients $(2.0 \%)$ did not have DXA in the femoral neck (right) or total hip. The characteristics of the participants are presented in Table 2 and Supplementary Figure 1. All our participants were aged or over 40 . The difference in gender composition $(p=0.256)$ and age $(60.4 \pm 10.4$ vs. 59.4 $\pm 10.3, p=0.275$ ) between $\mathrm{HC}$ and patients was not significant. Although the BMI of $\mathrm{HC}$ was higher than those with RA $(22.8 \pm 3.62$ vs. $22.1 \pm 3.39, p=0.031)$, the composition of BMI groups [26, 27] showed no significant difference. HC had more postmenopausal women and even those with early menopause than patients with RA ( $88.4 \%$ vs. $70.7 \%, p<0.001)$. Serum calcifediol $[25(\mathrm{OH}) \mathrm{D} 3]$ level was lower in $\mathrm{HC}(65.6 \pm 22.1$ vs. $76.7 \pm 32.9, p=$ 0.006); insufficiency of vitamin D3 and hypovitaminosis D were also more prevalent in RA patients $(64.9 \%$ vs. $54.5 \%$, $p$ for trend test $=0.046$ ). The median disease duration of RA patients was $5.5[1.5 ; 13.0]$.

\section{Difference and changing trend of BMD}

We divided age into five groups by 5 years, according to van Staa TP, et al. grouping method [28], for analyzing the difference and changing trend of BMD of each site between $\mathrm{HC}$ and RA patients. The detailed analysis showed that except for those were aged 40-45, RA patients in all age groups had lower BMD in lumbar spine 
Table 2 Characteristics of the participants

\begin{tabular}{|c|c|c|c|}
\hline Characteristics & $\mathrm{HC}, n==198$ & $\mathrm{RA}, n=405$ & $p$ \\
\hline \multicolumn{4}{|l|}{ Demographic } \\
\hline Age, years, mean (SD) & $60.4(10 c .4)$ & $59.4(10.3)$ & 0.275 \\
\hline Disease duration, years, median [IQR] & NA & $5.5[1.5 ; 13.0]$ & NA \\
\hline $\mathrm{BMI}, \mathrm{Kg} / \mathrm{m}^{2}$, mean (SD) & $22.8(3.6)$ & $22.1(3.4)$ & 0.031 \\
\hline Female, n (\%) & $146(73.7)$ & $317(78.3)$ & 0.256 \\
\hline Menopause status of female, n (\%) & & & $<0.001^{*}$ \\
\hline Post-menopause, age $>45$ & $104(71.2)$ & $186(58.7)$ & \\
\hline Early menopause, age $\leq 45$ & $25(17.1)$ & $38(12.0)$ & \\
\hline \multicolumn{4}{|l|}{ Lifestyle } \\
\hline Smoking, ever or current, yes, n (\%) & $17(8.6)$ & $36(8.9)$ & 0.937 \\
\hline Drinking, ever or current, yes, n (\%) & $18(9.1)$ & $18(4.4)$ & 0.035 \\
\hline \multicolumn{4}{|l|}{ Medical history } \\
\hline Diabetes mellitus & $35(17.7)$ & $47(11.6)$ & 0.055 \\
\hline Hypertension & $75(37.9)$ & $77(19.0)$ & $<0.001$ \\
\hline Coronary heart disease & $20(10.1)$ & $20(4.9)$ & 0.027 \\
\hline Hyperuricemia & $15(7.6)$ & $43(10.6)$ & 0.297 \\
\hline Dyslipidemia & $58(29.3)$ & $56(13.8)$ & $<0.001$ \\
\hline Femoral neck necrosis & $1(0.5)$ & $8(2.0)$ & 0.268 \\
\hline Osteoporotic fracture & 0 & $20(4.9)$ & NA \\
\hline Anti-osteoporotic medication & $6(3.0)$ & $29(7.2)$ & 0.641 \\
\hline \multicolumn{4}{|l|}{ Laboratory } \\
\hline Serum calcium level, mmol /L, mean (SD) & $2.4(0.2)$ & $2.3(0.1)$ & $<0.001$ \\
\hline Serum phosphate level, mmol /L, mean (SD) & $1.9(8.1)$ & $1.2(0.4)$ & 0.272 \\
\hline Serum creatinine level, $\mu \mathrm{mol} / L$, mean (SD) & $67.2(32.9)$ & $62.6(20.5)$ & 0.086 \\
\hline Serum Uric acid level, $\mu \mathrm{mol} / \mathrm{L}$, mean (SD) & $327.9(101.2)$ & $314.1(103.9)$ & 0.146 \\
\hline Serum 25(OH)D3 level, nmol /L, mean (SD) & $65.6(22.1)$ & $76.7(32.9)$ & 0.006 \\
\hline Vitamin D insufficiency, yes, n (\%) & $65(32.8)$ & $145(35.8)$ & $0.046^{*}$ \\
\hline Hypovitaminosis D, yes, n (\%) & $43(21.7)$ & $118(29.1)$ & $0.046^{*}$ \\
\hline
\end{tabular}

*: $p$ for trend with Cochran-Armitage test; HC Healthy controls, RA Rheumatoid arthritis, hypovitaminosis D Serum 25(OH)D3 $<50 \mathrm{nmol} / \mathrm{L}$, VitD3 deficiency Serum $25(\mathrm{OH}) \mathrm{D} 3<75 \mathrm{nmol} / \mathrm{L}$

2-4 (supplementary Table 1). BMD of the femoral neck was consistently lower in patients with RA at all age stages. However, except for patients who were 40-45 and 56-60 years old, BMD of the total hip was significantly lower than HC.

The visually intuitionistic changing trends of BMD of 3 measurement sites were both fluctuating but overall declining with age (Supplementary Figure 3a). The numerically highest decline in the BMD of the lumbar spine was found in RA patients aged over 50. BMI was positively correlated to BMD in all measurement sites for both patients and HC (see supplementary Figure 3b).

\section{Prevalence of bone loss}

Since participants in our study were mid-aged or older, only 93 people were diagnosed with Z-score. We did not find a significant difference between $\mathrm{HC}$ and RA patients in any BMD measurement site.

In male participants aged at and over 50 and postmenopausal women, we noticed that RA patients were more likely to comorbid with osteopenia (24.1\% vs. $32.3 \%)$ and OP $(48.8 \%$ vs. $57.3 \%, \mathrm{p}$ for trend $<0.001)$ only in the lumbar spine. However, the prevalence of osteopenia and OP in any site, or femoral neck, or total hip showed no difference between cases and controls (Supplementary Table 2 and Supplementary Figure 2).

\section{Risk factors for bone loss in RA patients}

The three modeling approaches for three sites resulted in 18 different sets of variables associated with osteopenia and OP (9 sets of each). Two variables were consistently selected across all models, 'age' and 'BMI' (except 
'BMI' in model B of the lumbar spine in osteopenia). Details of models were shown in (Supplementary Table 3). Finally, for osteopenia, model A, Model B, and Model A were the best for the lumbar spine, femoral neck, and total hip, respectively. For OP, model A, model B, and model B were optimal for the lumbar spine, femoral neck, and total hip, respectively. Odd ratios of the selected models were shown in Table 3. Aging was a general risk factor for each site and osteopenia (OR: $1.11 \sim$ 1.17 ) and osteoporosis (OR: $1.15 \sim 1.25)$. On the contrary, increasing BMI was a common protective factor for BMD (for osteopenia, OR: 0.84-0.88; for OP, OR: $0.62-0.68)$. Higher serum $25(\mathrm{OH}) \mathrm{D} 3$ level was a protective factor for lumbar spine [for osteopenia, OR: 0.99(0.98-1.00); for OP, 0.97(0.96-0.98)] and osteoporosis in femoral neck [OR: 0.98(0.96,0.99)]. Besides, results suggested that using TNFi in the last 1 year was a protective factor for osteopenia in either the lumbar spine [OR: $0.27(0.08,0.84)$ ] or total hip [OR: $0.37(0.14$, $0.93)]$. Increased serum uric acid was a risk factor for osteoporosis in total hip [OR: 1.01(1.00, 1.01)].

\section{Discussion}

Our study detected that in male participants aged at and over 50 and postmenopausal women, the frequency of osteopenia and osteoporosis in the lumbar spine of inpatients with RA was significantly 1.3 -fold and 1.2 -fold higher than these in healthy counterparts, respectively. The overall frequency of OP in our RA cohort is higher than previous studies, which reported $22.4-46.8 \%$ [29, 30]; osteopenia is in the range of the previous reported
$25 \% \sim 34 \%[7,8]$. Although the significant prevalence of bone loss was only found in the lumbar spine, it was higher than the previous reported (from 31.5 to $36.2 \%$ ) $[3,4]$.

The age at which BMD of these sites drops sharply arrived earlier in RA patients, especially in the femoral neck. This point is a noticeable finding of the present study. It suggested that RA patients' turning points to develop into OPF maybe earlier in the femoral neck. However, in China, the femoral neck is not a routine monitoring choice but the lumbar spine. Overall, these findings suggest that the BMD of the femoral neck also needs appropriate and earlier management than the lumbar spine.

Except for well-documented risk factors (increasing age and lower BMI) consistently associated with the risk of osteopenia and osteoporosis among in-patients with RA, TNFi usage in the last 1 year was found a protective factor for osteopenia in the lumbar spine and total hip by covariates-preselected manually logistic regression. It suggested that using TNFi could not merely reduce disease activity but also protect BMD in the lumber spine and total hip. TNF- $\alpha$, a key proinflammatory cytokine in RA, can stimulate osteoclastogenesis via RANKL activation [31], leading to systemic bone loss. Since many observational studies had reported TNF- $\alpha$ blockers could either improve or stabilize BMD in the aforementioned measurement sites [14, 32], we forced 'the usage of TNFi in the last one year before DXA examination' into the logistic regression models. However, in our study, TNFi usage did not appear to influence BMD of the femoral

Table 3 Odd ratios of variables from selective models of 3 measurement sites

\begin{tabular}{|c|c|c|c|c|c|c|}
\hline \multirow{2}{*}{$\begin{array}{l}\text { Detective } \\
\text { sites }\end{array}$} & \multicolumn{3}{|l|}{ Osteopenia } & \multicolumn{3}{|l|}{ Osteoporosis } \\
\hline & Variables & Odd ratios $(95 \% \mathrm{Cl})$ & $p$ & Variables & Odd ratios $(95 \% \mathrm{Cl})$ & $P$ \\
\hline \multirow[t]{4}{*}{ Lumber spine $^{a}$} & Age & $1.15(1.10,1.21)$ & $<0.001$ & Age & $1.25(1.18,1.33)$ & $<0.001$ \\
\hline & BMI & $0.88(0.77,0.99)$ & 0.038 & BMI & $0.68(0.57,0.79)$ & $<0.001$ \\
\hline & Serum 25(OH)D3 level & $0.99(0.98,1.00)$ & 0.030 & Serum 25(OH)D3 level & $0.97(0.96,0.98)$ & $<0.001$ \\
\hline & TNFi usage in the last one year & $0.27(0.08,0.84)$ & 0.027 & & & \\
\hline \multirow[t]{6}{*}{ Femoral neck ${ }^{b}$} & Age & $1.17(1.12,1.22)$ & $<0.001$ & Age & $1.26(1.18,1.36)$ & $<0.001$ \\
\hline & BMI & $0.85(0.77,0.95)$ & 0.003 & BMI & $0.62(0.50,0.75)$ & $<0.001$ \\
\hline & Rheumatoid factor concentration & $1.00(0.99,1.02)$ & 0.183 & Serum 25(OH)D3 level & $0.98(0.96,0.99)$ & 0.002 \\
\hline & & & & sUA & $1.00(1.00,1.01)$ & 0.068 \\
\hline & & & & Disease duration & $1.00(0.89,1.13)$ & 0.967 \\
\hline & & & & Serum phosphate level & $1.87(0.48,29.95)$ & 0.631 \\
\hline \multirow[t]{3}{*}{ Total hip ${ }^{c}$} & Age & $1.11(1.08,1.15)$ & $<0.001$ & Age & $1.15(1.10,1.21$ & $<0.001$ \\
\hline & BMI & $0.84(0.77,0.92)$ & $<0.001$ & BMl & $0.68(0.58,0.78)$ & $<0.001$ \\
\hline & TNFi usage in the last one year & $0.37(0.14,0.93)$ & 0.040 & sUA & $1.01(1.00,1.01)$ & 0.001 \\
\hline
\end{tabular}

BMI Body mass index, 25(OH)D3 Calcifediol, TNFi Tumor necrosis factor-a inhibitor, sUA Serum uric acid level

${ }^{\text {a }}$ Preselected logistic regression (models A) were optimal for both osteopenia and osteoporosis in lumber spine

bLASSO (models B) were optimal for both osteopenia and osteoporosis in femoral neck (R)

${ }^{\mathrm{C}}$ Model $\mathrm{A}$ and $\mathrm{B}$ were optimal for osteopenia and osteoporosis respectively in total hip 
neck (i.e., was not selected by LASSO models). Actually, even we forced the 'TNFi usage' variable into the logistic regression models for osteopenia or OP in the femoral neck, it was not a significant influential factor (data were not showed) for BMD in this site.

As Chen et al. has pointed out, RA patients who received concomitant anti-osteoporotic therapy and bDMARDs would experience a satisfactory BMD preserving effect [33]. However, in the present study, the low using proportion of anti-osteoporotic drugs, including bisphosphonates and Teriparatideacetate in either $\mathrm{HC}$ or patients, might be responsible for the inconsistent results. Therefore, though we had forced the 'overall anti-osteoporotic medication history' into the logistic regression models, this variable could not significantly influence bone loss in RA and, eventually, did not enter the final sets of logistic regression models.

Sabbagh et al. [34] found that the inadequate Vitamin D status has a considerably strong association with disease activity in RA cases, and active RA with anti-CCP positivity was associated with lower BMD [35]. Our finding was similar partially, which indicated the need for proper evaluation of Vitamin D status in these patients to ensure the intake of the recommended amount of Vitamin D, but positive anti-CCP was not associated with bone loss in our study.

Serum uric acid (sUA) was found as a risk factor for reduced BMD in the total hip of RA patients (11.6\% patient with hyperuricemia and an sUA mean value of $314.1 \pm 103.9 \mu \mathrm{mol} / \mathrm{L}$, data were not shown). Several studies have demonstrated that sUA has bilateral effects on bone health. UA is linked to bone loss in hyperuricemia and gout, especially the increased risk of hip fracture $[36,37]$. However, UA is the primary antioxidant in human plasma and accounts for more than $60 \%$ of the capacity to scavenge free oxidative radicals [38]; thus, it acts as an antioxidant to prevent bone loss and osteoporosis when in the normal physiologic range $[39,40]$. Our finding suggested that in RA patients, proper management of hyperuricemia might benefit their hip bone mineral density, lowering the risk of subsequent osteoporotic fracture, which increases the mortality rate [41] and societal and economic cost [42].

This study has limitations. First, we did not specify the current or cumulative steroid dose and disease activity of patients. Second, we cannot exclude the possibility of patient selection bias because the three centers participating in this study were tertiary referral centers in South China. Therefore, BMD measurement rates in this study cannot represent the real rate of DXA in our country. Our analysis also ignored the possible variability that might be caused by different patterns or management of patients across centers. A mixed-effects logistic regression could improve the precision of the estimates.
Third, clinicians were more prone to advise in-patients with higher disease activity and longer disease duration and healthy subjects with higher well-documented risks to have DXA examination. Hence, our study revealed a higher prevalence of OP than previously reported. Due to the limitation of sample size and cross-sectional study, a prospective and large-scale follow-up is looked forward to in the future.

In conclusion, RA patients enrolled in the study were more prone and earlier to have bone loss than HC. Our study suggests more attention should be paid to measuring BMD in RA patients aging with lower BMI or hyperuricemia. Besides, serum vitamin $\mathrm{D}$ and all three measurement sites are recommended to check routinely. TNFi usage in the last year might benefit bone mass.

\section{Abbreviations}

RA: Rheumatoid arthritis; BMD: Bone mineral density; OP: Osteoporosis; TNFa: Tumor necrosis factor-a; RANKL: Receptor activator of nuclear factor kappa B ligand; OPF: Osteoporotic fracture; GCs: Glucocorticoids; BMI: Body mass index; TNFi: TNF inhibitor; HC: Healthy controls; ACR: American college of rheumatology; EULAR: European league against rheumatism; DXA: Dualenergy X-ray absorptiometry; NSAIDs: Non-steroidal anti-inflammatory drugs; anti-CCP: Anti-cyclic citrullinated peptide antibodies; AKA: Antikeratin antibodies; RA33: Anti-RA33 antibodies; SD: Standard error; LASSO: Least absolute shrinkage and selection operator; RF: Random forest; OOB: Out-ofbag; 25(OH)D3: Calcifediol; sCr: Serum creatine level; sUA: Serum uric acid

\section{Supplementary Information}

The online version contains supplementary material available at https://doi. org/10.1186/s12891-021-04403-5.

Additional file 1: Figure S1. Distribution of gender (a) and BMI(b) of patients with RA and HC. *: p for trend with Cochran-Armitage test. Figure S2. *: $p$ for trend with Cochran-Armitage test. Figure S3. The changing trend of BMD with aging (a) and weight-gaining (b) of patients with RA and HC. Table S1. BMD in three detective sites of all participants according to age groups. Table S2. DXA results of 'score below the expected range for age'. Table S3. The three approaches development for the model of osteopenia, osteoporosis and their performance.

\section{Acknowledgments}

We thank all patients involved in the study.

\section{Authors' contributions}

YLC and WJL contributed to conceiving and design of the study, revised the manuscript. ZRH and LZ contributed equally to draft the manuscript and prepared figures; ZRH was responsible for analyzing the data; $Z R H, L Z, Z M L$ was for interpreting the results; ZML, CLZ, HL, SMX, and JJZ contributed to collect data and revise the manuscript. All authors approved the publication.

\section{Funding}

Not applicable.

\section{Availability of data and materials}

Because of the confidentiality of the data used for this study and the strict privacy policy of the Third Affiliated Hospital of Sun Yat-sen University, Zhuhai Hospital of Guangdong Chinese Medicine, Ganzhou Municipal Hospital, and Fujian Provincial Hospital, stating the data be kept among the designated research personnel only. Access to the computer code used in this research is available by request to the corresponding author. 


\section{Declarations}

\section{Ethics approval and consent to participate}

The study was approved by the ethical approval were obtained from the Ethics Committee of the Third Affiliated Hospital, Sun Yat-sen University. The study was performed following the Declaration of Helsinki principles, and informed consent was obtained from all individual participants included in the study. The ethical registration no. of the study was [2018]02-283-01.

\section{Consent for publication}

Not applicable.

\section{Competing interests}

The authors declare no conflicts of interest.

\section{Author details}

'Division of Rheumatology, the Third Affiliated Hospital of Sun Yat-sen University, No.600, Tianhe Road, Tianhe District, Guangzhou City 51000, China. ${ }^{2}$ Division of Rheumatology, Zhuhai Hospital of Guangdong Provincial Hospital of Chinese Medicine, No.53, Ji'Da Jingle Road, Xiangzhou District, Zhuhai City 519015, China. ${ }^{3}$ Division of Cardiology, the Third Affiliated Hospital of Sun Yat-sen University, No.600, Tianhe Road, Tianhe District, Guangzhou City 51000, China. ${ }^{4}$ Division of Rheumatology, Ganzhou Municipal Hospital, No.49, Dagong Road, Ganzhou City 341000, China ${ }^{5}$ Division of Rheumatology, Fujian Provincial Hospital, No. 134, Dongjie Road, Fuzhou City 350000, China.

\section{Received: 2 March 2021 Accepted: 21 May 2021}

Published online: 12 June 2021

\section{References}

1. Harris ED Jr. Rheumatoid arthritis. Pathophysiology and implications for therapy. N Engl J Med. 1990;322(18):1277-89. https://doi.org/10.1056/NEJM1 99005033221805.

2. Lee DM, Weinblatt ME. Rheumatoid arthritis. Lancet. 2001;358(9285):903-11. https://doi.org/10.1016/S0140-6736(01)06075-5.

3. Haugeberg G, Uhlig T, Falch JA, Halse JI, Kvien TK. Bone mineral density and frequency of osteoporosis in female patients with rheumatoid arthritis: results from 394 patients in the Oslo County rheumatoid arthritis register. Arthritis Rheum. 2000;43(3):522-30. https://doi.org/10.1002/1529-0131 (200003)43:3<522::AID-ANR7>3.0.CO:2-Y.

4. Sinigaglia L, Nervetti A, Mela Q, Bianchi G, Del Puente A, Di Munno O, et al. A multicenter cross sectional study on bone mineral density in rheumatoid arthritis. Italian study group on bone mass in rheumatoid arthritis. J Rheumatol. 2000;27(11):2582-9.

5. Lin YC, Li YH, Chang CH, Hu CC, Chen DW, Hsieh PH, et al. Rheumatoid arthritis patients with hip fracture: a nationwide study. Osteoporosis Int. 2015;26(2):811-7. https://doi.org/10.1007/s00198-014-2968-y.

6. Shin K, Park S-H, Park W, Baek HJ, Lee YJ, Kang SW, et al. Monthly oral ibandronate reduces bone loss in korean women with rheumatoid arthritis and osteopenia receiving long-term glucocorticoids: a 48-week Doubleblinded Randomized Placebo-controlled Investigator-initiated Trial. Clin Ther. 2017:39(2):268-278.e262.

7. Mikuls TR, Saag KG, Curtis J, Bridges SL Jr, Alarcon GS, Westfall AO, et al. Prevalence of osteoporosis and osteopenia among African Americans with early rheumatoid arthritis: the impact of ethnic-specific normative data. J Natl Med Assoc. 2005;97(8):1155-60.

8. Guler-Yuksel M, Bijsterbosch J, Goekoop-Ruiterman YP, de Vries-Bouwstra JK, Ronday HK, Peeters AJ, et al. Bone mineral density in patients with recently diagnosed, active rheumatoid arthritis. Ann Rheum Dis. 2007;66(11):1508-12. https://doi.org/10.1136/ard.2007.070839.

9. Gilboe IM, Kvien TK, Haugeberg G, Husby G. Bone mineral density in systemic lupus erythematosus: comparison with rheumatoid arthritis and healthy controls. Ann Rheum Dis. 2000:59(2):110-5. https://doi.org/10.1136/a rd.59.2.110.

10. Arain SR, Riaz A, Nazir L, Umer TP, Rasool T. LOW bone mineral density among patients with newly diagnosed rheumatoid arthritis. J Ayub Med Coll Abbottabad. 2016:28(1):175-8.

11. Raterman HG, Bultink IEM, Lems WF. Current treatments and new developments in the management of glucocorticoid-induced osteoporosis. Drugs. 2019;79(10):1065-87. https://doi.org/10.1007/s40265-019-01145-6.
12. Sapir-Koren R, Livshits G. Postmenopausal osteoporosis in rheumatoid arthritis: the estrogen deficiency-immune mechanisms link. Bone. 2017;103: 102-15. https://doi.org/10.1016/j.bone.2017.06.020.

13. Lange U, Teichmann J, Müller-Ladner U, Strunk J. Increase in bone mineral density of patients with rheumatoid arthritis treated with anti-TNF-a antibody: a prospective open-label pilot study. Rheumatology. 2005;44(12): 1546-8. https://doi.org/10.1093/rheumatology/kei082.

14. Marotte H, Pallot-Prades B, Grange L, Gaudin P, Alexandre C, Miossec P. A 1year case-control study in patients with rheumatoid arthritis indicates prevention of loss of bone mineral density in both responders and nonresponders to infliximab. Arthritis Res Ther. 2007;9(3):R61. https://doi. org/10.1186/ar2219.

15. Gong X, Xu SQ, Tong H, Wang XR, Zong HX, Pan MJ, et al. Correlation between systemic osteoporosis and local bone erosion with rheumatoid arthritis patients in Chinese population. Rheumatology (Oxford). 2019. https://doi.org/10.1093/rheumatology/kez042.

16. Yan S, Cui Y, Zhang X, Zhang G, Dong G, Feng Y, et al. The incidence of extra-articular manifestations in southern Chinese patients with inflammatory joint diseases. Int J Rheum Dis. 2019;22(9):1686-94. https://doi. org/10.1111/1756-185X.13657.

17. Hu Z, Xu S, Lin H, Ni W, Yang Q, Qi J, et al. Prevalence and risk factors for bone loss in southern Chinese with rheumatic diseases. BMC Musculoskelet Disord. 2020;21(1):416. https://doi.org/10.1186/s12891-020-03403-1.

18. Kay J, Upchurch KS. ACR/EULAR 2010 rheumatoid arthritis classification criteria. Rheumatology (Oxford). 2012;51(Suppl 6):vi5-9.

19. Prevention and management of osteoporosis. World Health Organ Tech Rep Ser 2003, 921:1-164, back cover.

20. Holick MF. Vitamin D deficiency. N Engl J Med. 2007;357(3):266-81. https:// doi.org/10.1056/NEJMra070553.

21. Chen $\mathrm{P}, \mathrm{Li} Z \mathrm{Z}, \mathrm{Hu}$ Y. Prevalence of osteoporosis in China: a meta-analysis and systematic review. BMC Public Health. 2016;16(1):1039. https://doi.org/10.11 86/s12889-016-3712-7

22. Steyerberg EW, Eijkemans MJ, Harrell FE Jr, Habbema JD. Prognostic modelling with logistic regression analysis: a comparison of selection and estimation methods in small data sets. Stat Med. 2000;19(8):1059-79. https://doi.org/10.1002/(SICI)1097-0258(20000430)19:8<1059":AID-SIM412>3. $0 . \mathrm{CO} ; 2-0$.

23. Friedman $J \mathrm{H}$, Hastie T, Tibshirani R. Regularization Paths for Generalized Linear Models via Coordinate Descent. J Stat Softw. 2010;33(1):22.

24. Breiman L. Random forests. Mach Learn. 2001;45(1):5-32. https://doi.org/10.1 023/A:1010933404324.

25. Altmann A, Tolosi L, Sander O, Lengauer T. Permutation importance: A corrected feature importance measure. Bioinformatics (Oxford, England). 2010:26:1340-7

26. WHO Expert Consultation. Appropriate body-mass index for Asian populations and its implications for policy and intervention strategies. Lancet. 2004:363(9403):157-63.

27. Wildman RP, Gu D, Reynolds K, Duan X, He J. Appropriate body mass index and waist circumference cutoffs for categorization of overweight and central adiposity among Chinese adults. Am J Clin Nutr. 2004;80(5):1129-36. https://doi.org/10.1093/ajen/80.5.1129.

28. van Staa TP, Geusens P, Bijlsma JWJ, Leufkens HGM, Cooper C. Clinical assessment of the long-term risk of fracture in patients with rheumatoid arthritis. Arthritis Rheum. 2006;54(10):3104-12. https://doi.org/10.1002/art.22117.

29. Kweon S-M, Sohn DH, Park J-H, Koh JH, Park E-K, Lee H-N, et al. Male patients with rheumatoid arthritis have an increased risk of osteoporosis: frequency and risk factors. Medicine. 2018;97(24):e11122. https://doi.org/10.1 097/MD.0000000000011122

30. Lee JH, Sung YK, Choi CB, Cho SK, Bang SY, Choe JY, et al. The frequency of and risk factors for osteoporosis in Korean patients with rheumatoid arthritis. BMC Musculoskelet Disord. 2016;17(1):98. https://doi.org/10.1186/ s12891-016-0952-8.

31. Osta B, Benedetti G, Miossec P. Classical and paradoxical effects of TNF-a on bone homeostasis. Front Immunol. 2014:5:48.

32. Eekman DA, Vis M, Bultink IEM, Kuik DJ, Voskuyl AE, Dijkmans BAC, et al. Stable bone mineral density in lumbar spine and hip in contrast to bone loss in the hands during long-term treatment with infliximab in patients with rheumatoid arthritis. Ann Rheum Dis. 2011;70(2):389-90. https://doi. org/10.1136/ard.2009.127787

33. Chen J-F, Hsu C-Y, Yu S-F, Ko C-H, Chiu W-C, Lai H-M, et al. The impact of long-term biologics/target therapy on bone mineral density in rheumatoid 
arthritis: a propensity score-matched analysis. Rheumatology (Oxford, England). 2020;59(9):2471-80.

34. Sabbagh Z, Markland J, Vatanparast H. Vitamin D status is associated with disease activity among rheumatology outpatients. Nutrients. 2013;5(7):226875. https://doi.org/10.3390/nu5072268.

35. Ahmad HA, Alemao E, Guo Z, lannaccone CK, Frits ML, Weinblatt M, et al. Association of low bone mineral density with anti-citrullinated protein antibody positivity and disease activity in established rheumatoid arthritis: findings from a US observational cohort. Adv Ther. 2018;35(2):232-42. https://doi.org/10.1007/s12325-017-0657-x.

36. Paik JM, Kim SC, Feskanich D, Choi HK, Solomon DH, Curhan GC. Gout and risk of fracture in women: a prospective cohort study. Arthritis Rheumatol (Hoboken, NJ). 2017;69(2):422-8.

37. Mehta T, Bůžková P, Sarnak MJ, Chonchol M, Cauley JA, Wallace E, et al. Serum urate levels and the risk of hip fractures: data from the cardiovascular health study. Metab Clin Exp. 2015;64(3):438-46. https://doi.org/10.1016/j. metabol.2014.11.006

38. Fabbrini E, Serafini M, Colic Baric I, Hazen SL, Klein S. Effect of plasma uric acid on antioxidant capacity, oxidative stress, and insulin sensitivity in obese subjects. Diabetes. 2014;63(3):976-81. https://doi.org/10.2337/db13-1396.

39. Ishii S, Miyao M, Mizuno Y, Tanaka-Ishikawa M, Akishita M, Ouchi Y. Association between serum uric acid and lumbar spine bone mineral density in peri- and postmenopausal Japanese women. Osteoporos Int. 2014;25(3):1099-105. https://doi.org/10.1007/s00198-013-2571-7.

40. Makovey J, Macara M, Chen JS, Hayward CS, March L, Seibel MJ, et al. Serum uric acid plays a protective role for bone loss in peri- and postmenopausal women: a longitudinal study. Bone. 2013;52(1):400-6. https://doi.org/10.101 6/j.bone.2012.10.025

41. Guzon-lllescas O, Perez Fernandez E, Crespí Villarias N, Quirós Donate FJ, Peña M, Alonso-Blas C, et al. Mortality after osteoporotic hip fracture: incidence, trends, and associated factors. J Orthop Surg Res. 2019;14(1):203. https://doi.org/10.1186/s13018-019-1226-6.

42. Caeiro JR, Bartra A, Mesa-Ramos M, Etxebarría Í, Montejo J, Carpintero P, et al. Burden of first osteoporotic hip fracture in Spain: a prospective, 12month, Observational Study. Calcif Tissue Int. 2017;100(1):29-39. https://doi. org/10.1007/s00223-016-0193-8

\section{Publisher's Note}

Springer Nature remains neutral with regard to jurisdictional claims in published maps and institutional affiliations.

Ready to submit your research? Choose BMC and benefit from:

- fast, convenient online submission

- thorough peer review by experienced researchers in your field

- rapid publication on acceptance

- support for research data, including large and complex data types

- gold Open Access which fosters wider collaboration and increased citations

- maximum visibility for your research: over $100 \mathrm{M}$ website views per year

At BMC, research is always in progress.

Learn more biomedcentral.com/submissions 